\title{
A Profile of Undergraduate Student Parents in Canada
}

\author{
Tricia M. van Rhijn, Trudy Smit Quosai, Donna S. Lero \\ University of Guelph
}

\begin{abstract}
Student parents are a significant minority population on Canadian postsecondary campuses. As research exploring this population has been extremely limited to date, this study provides the first national profile of Canadian student parents. We explore student parent enrolment patterns over time and examine current demographic characteristics. The data for this study were drawn from two datasets collected by Statistics Canada: the Labour Force Survey 1976-2005 and the Survey of Labour and Income Dynamics 2004 cross-sectional data file. Student parents accounted for between $11 \%$ and $16 \%$ of all post-secondary enrolment between 1976 and 2005. Further analyses explore participation patterns based on type of institution (college/ university), study status (full-/ part-time study), age, gender, and marital status. Future research directions and implications for policies and institutional practice are discussed.
\end{abstract}

\section{RÉSUMÉ}

Les étudiants qui sont aussi parents représentent une population minoritaire d'importance sur les campus postsecondaires canadiens. Puisque la recherche portant sur cette population demeure extrêmement limitée à ce jour, l'étude qui suit constitue le premier profil national d'étudiants canadiens qui sont aussi parents. On y explore les modèles d'inscription de ces étudiants au fil du temps et on y examine les caractéristiques démographiques actuelles. Les données de cette étude ont été prises de deux sources recueillies par Statistique Canada : la "Labour Force Survey 1976-2005 » et la « Enquête sur la dynamique du travail et du revenu, 2004 [Canada]: Fichier d'enquête transversale principale ». Les étudiants qui sont aussi parents représentent entre $11 \%$ et $16 \%$ de toutes les inscriptions postsecondaires entre 1976 et 2005. D'autres 
analyses explorent les modèles de participation fondés sur le type d'institution (collège ou université), le statut de l'étudiant (temps plein ou temps partiel), l'âge, le sexe et le statut familial. On y discute également de la direction des recherches futures, ainsi que des implications pour la rédaction de politiques et pour la pratique en milieu institutionnel.

\section{INTRODUCTION}

Post-secondary education (PSE) is an increasingly important component of human capital for individuals and for societies that takes on even greater importance as a factor in Canada's economic competitiveness as the population ages and the labour force shrinks. Education is also a critical determinant of health and well-being for individuals and families over the life course (Pascarella \& Terenzini, 2005; Ungerleider \& Burns, 2004). In addition, times of economic uncertainty and job losses can lead to increased demands for job retraining and other career changes, often involving the need to obtain or further one's education or credentials. For these reasons and others, governments and institutions are carefully examining factors that impede access to PSE and create barriers to students' persistence and completion of their chosen programs. One unique group of post-secondary students is student parents. Research exploring this population has been quite limited to date; in fact, Holmes's (2005) report, utilizing data from the 2002 Canadian Undergraduate Student Survey and the Canadian College Student Survey, provides the only previous large-scale, Canadian analysis including student parents. To provide an important basis for future research, this paper presents the first national profile of the undergraduate student parent population in Canada. ${ }^{1}$

\section{Student Parents in PSE}

Although student parents are often grouped into the category of mature students, their needs differ significantly from unencumbered mature students. Additionally, student parents are a heterogeneous group including young parents who are attempting to stay on track educationally in spite of early childbearing and older parents returning to school as adult learners to pursue a college or university education. Student parents may be single or partnered, attending PSE on a fulltime or part-time basis, and may also be employed in addition to attending school.

Student parents face many of the same barriers and challenges as traditional students in PSE programs; however, their situation is complicated by having additional time demands related to family and employment, additional economic demands related to family expenses and forgone income, and the challenge of fitting into an educational system designed for traditional (i.e., young, full-time) students. Student parents may have difficulty studying on a full-time basis, attending classes at scheduled times, finding appropriate child care, and accessing traditional forms of financial assistance because of limitations placed on eligibility. 


\section{LITERATURE REVIEW}

Research has demonstrated that student parents constitute a small, but important portion of college and university populations. Holmes (2005) provides the only previous estimate of the Canadian student parent population, estimating that $8 \%$ of university and $22 \%$ of college students had dependent children under the age of 18 in 2001-2002. Not surprisingly, student parents were found to differ in several significant ways from their more traditionally aged and circumstanced student counterparts (i.e., dependent students aged 18 to 22) in that they were older on average, more likely to be in part-time studies, and worked longer hours for pay than other students (Holmes, 2005).

The presence of children acts as a barrier to participating in and completing PSE for young parents (Butlin, 1999; Lambert, Zeman, Allen, \& Bussière, 2004; Looker, 1997). Young parents are more likely to delay participating in PSE than those without children and this effect is most dramatic for women (Dubois, 2006). Single mothers, in particular, experience multiple challenges with respect to postsecondary participation. Despite overall economic improvements in recent years, single mothers are still over-represented among low-income families (Statistics Canada, 2009) and those with less education who experience more barriers to participating in PSE face particular challenges to earning an adequate income (Berger, Motte, \& Parkin, 2009).

Although higher educational attainment typically translates into better job prospects and higher earnings, having some post-secondary education without finishing a credential does not result in significant improvements over and above high school completion (Statistics Canada, 2004). This finding underscores the importance of not just participating in post-secondary education, but also of successful program completion. There is evidence that undergraduate student parents obtain high grades in their courses (Holmes, 2005); however, adult students are also more likely to drop out or interrupt their post-secondary studies than traditional students (Grayson \& Grayson, 2003; Holmes, 2005). When students drop out of PSE, there is a loss of potential human capital and decreased ability to compete successfully for employment in an increasingly knowledge-based economy. For student parents, there are additional costs to the family, including financial sacrifice and forgone wages, lost time with a partner and children, and increased stress and strain. Promoting the retention and success of student parents is important both for promoting economic self-sufficiency (i.e., higher earnings) and for reducing family distress.

Although the reasons student parents face an increased likelihood of interrupting their studies have not been clearly demonstrated, the unique challenges and stressors they face may play a role. Student parents are found to experience increased role strain (Home, 1997) and more stress than traditional students when entering the post-secondary environment (Padula, 1994). The transition to postsecondary education is generally assumed to be a stressful transition but may be particularly stressful for student parents returning to school after a long absence 
from an educational environment. Student parents are challenged by interacting with younger peers with differing values, interests, and priorities (Padula, 1994). As student parents are more likely to participate on a part-time basis and to work more hours while studying (Holmes, 2005), it is likely that successful completion of PSE may also be affected by the challenges student parents face combining employment and family responsibilities with their studies.

In addition to role strain and other stressors, financial challenges may act as a particular barrier for student parents. Access to financial resources is an increasingly important factor for many students. Financial resources are required to pay for PSE expenses including tuition, books, and additional fees. Student parents typically face other expenses such as child care and those related to maintaining a household, expenses that continue while earnings may be reduced or eliminated in order to attend classes. Partly for these reasons, there is evidence that student parents incur higher education-related debts than other students (Allen \& Vaillancourt, 2004) and are found to be more likely to interrupt their studies for financial reasons (Holmes, 2005).

There are existing federal and provincial/territorial policies and programs available to provide financial support to post-secondary students. Additionally, some policies have been initiated and/or expanded in the past decade, such as specific supports for student parents (e.g., the Canada Study Grant for Students with Dependents and the Ontario Child Care Bursary). However, student parents' unique circumstances can act to reduce their access to some of the programs. For example, eligibility for the Canada Student Loans Program is affected by the student's and his or her partner's income and assets. Students who live with a spouse or partner often have less access to government assistance and need to make greater use of private savings, loans, or employment income (EKOS Research Associates, 2003). Financing a PSE program may require liquidating family assets such as a car, a home, and RRSPs, something that is either not possible or very problematic for most student parents and their families.

Student parents may also choose to study part-time, perhaps because of inadequate access to affordable child care or to maintain employment. Although the Canada Student Loans Program offers loans to part-time students, they are limited to a $\$ 4,000$ cumulative maximum and require interest payments while the student is in school, providing limited support for student parents (Lero, Smit Quosai, \& van Rhijn, 2007). The choice of full-time versus part-time studies can also act as a double bind for student parents because studying part-time often results in restricted access to financial aid including scholarships, bursaries, and loans. Evidently, existing policies and programs were designed primarily to provide support for younger, unencumbered students who can afford to enrol on a full-time basis.

This introduction demonstrates some of the unique challenges faced by student parents. As research on this topic is very limited, especially in Canada, a further understanding of the unique circumstances of student parents is required to improve student parents' access to, persistence in, and completion of PSE programs. 


\section{STUDY PURPOSE AND HYPOTHESES}

This paper aims to provide previously unavailable information about national-level, long-term participation trends and descriptive information about student parents from a program of research designed to advance understanding of Canadian student parents in PSE. Based on a funded research project for Human Resources and Social Development Canada (Lero et al., 2007), the purpose of this paper is to explore student parent enrolment patterns over time and examine their demographic characteristics.

While it is generally understood that, based on their parental status, the experiences of student parents in post-secondary study likely differ from those of traditional students, the impact of these differences on participation and enrolment patterns has not yet been explored. Given the limited amount of research attention to this topic, there is little work on which to found specific hypotheses for this study; however, we hypothesize that student parent participation patterns will differ from students who are not parents over the 30-year period of time examined (1976-2005). In particular, based on Holmes's findings (2005), we expect that student parents are more likely to study in college, be enrolled in part-time studies, and be older than traditional students. We also examined other demographic characteristics where differences in participation patterns might exist, including gender, marital status, employment, and income.

Two Statistics Canada datasets, the Labour Force Survey (LFS) and the Survey of Labour and Income Dynamics (SLID) were utilized for this study. The datasets were used to first examine the national participation patterns of Canadian student parents over time compared with non-parents, and to explore possible regional differences. Next a closer examination of student parents' participation patterns over time was conducted to answer the study hypotheses based on type of institution (college or university), study status (full-time or part-time study), age and gender of the student parent, marital status, employment, and income.

\section{METHOD}

There are many data sets available that provide information about Canadian students. Of these, only a subset identifies whether or not the student has dependent children or provides sufficient information about student characteristics. For example, census data available at the time of this research did not include the level of post-secondary study (i.e., college or university), and adult learning surveys such as the Workplace and Employee Survey and the Adult Education and Training Survey exclude learners younger than age 25 and present challenges related to sample size. It is also important to note that the major source of demographic information about students (the Enhanced Student Information System) does not provide information about dependants. As well, a survey of student engagement (the National Survey of Student Engagement) that is gaining popularity also does not ask about dependants. Because no single data source could provide compre- 
hensive information about student parents in PSE, two Statistics Canada datasets were analysed for the purposes of this paper: the Labour Force Survey 1976-2005 2 and the Survey of Labour and Income Dynamics 2004 cross-sectional data file. ${ }^{3}$ Both were accessed through the South-Western Ontario Research Data Centre. LFS data were analyzed to examine the trends in PSE participation over time comparing student parents with students who are not parents. SLID data were used to provide more detailed information about student parents. As neither of the surveys asked respondents directly about their level of university study (e.g., undergraduate or graduate), we excluded all respondents who were enrolled in a university program but had already obtained an undergraduate degree. It is possible that some students may have been excluded who were completing a second undergraduate degree or professional certification at the bachelor's level.

Analyses, conducted using SPSS, were primarily descriptive, including means, medians, and cross-tabulations of frequencies. Variables examined included both socio-demographic characteristics and details about the post-secondary program. Socio-demographic characteristics included age, gender, marital status, age and number of children under 18, and employment status. Post-secondary program details included type of institution, study status, and province/territory of study.

\section{FINDINGS}

\section{National Participation Patterns and Regional Differences}

National participation patterns (LFS 1976 to 2005 data)

Overall, participation in post-secondary programs underwent a period of considerable growth during the 30-year period from 1976 to 2005. The total number of students increased by $111 \%$ from 585,000 to 1,234,100 (Figure 1). During that time, growth in the participation of non-parent students outpaced the growth of student parents (113\% and $96 \%$, respectively). As a percentage of all post-secondary students, student parents accounted for between $11 \%$ and $16 \%$ of enrolment, increasing from 13\% in 1976 to $16 \%$ in 1991, then declining to a low of $11 \%$ in 2004 (Figure 2).

\section{Regional differences (SLID 2004 data)}

There were some regional differences apparent in post-secondary enrolment. Overall, student parents accounted for between $12 \%$ and $21 \%$ of total post-secondary enrolment in each jurisdiction (Figure 3). As a proportion of all post-secondary enrolment, student parent enrolment was higher in the Prairie provinces, consisting of Manitoba, Saskatchewan, and Alberta (21\%), and the Atlantic Region $(16 \%)$. Areas with lower student parent enrolment included Quebec (12\%), Ontario (13\%), and British Columbia (13\%). College student parents in Quebec represented a much smaller percentage of post-secondary enrolment than elsewhere in Canada $(6 \%)$, though this percentage is likely related to the younger age at which students begin CEGEP in Quebec. In both the Prairies and the Atlantic Region, $28 \%$ of all college students were parents, representing a greater percentage of college students than in other regions. 

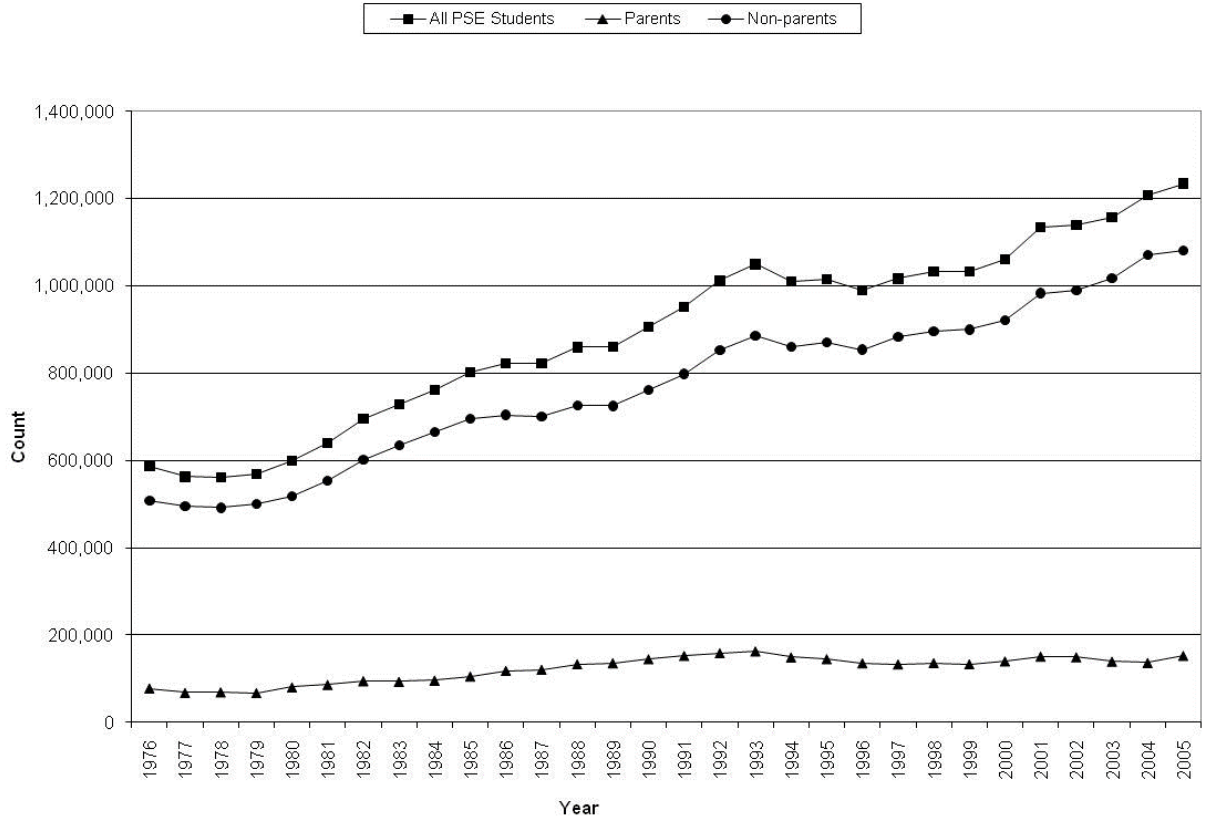

Figure 1. Student Parent and Non-Parent Participation in Post-Secondary Education, Labour Force Survey, Canada 1976-2005

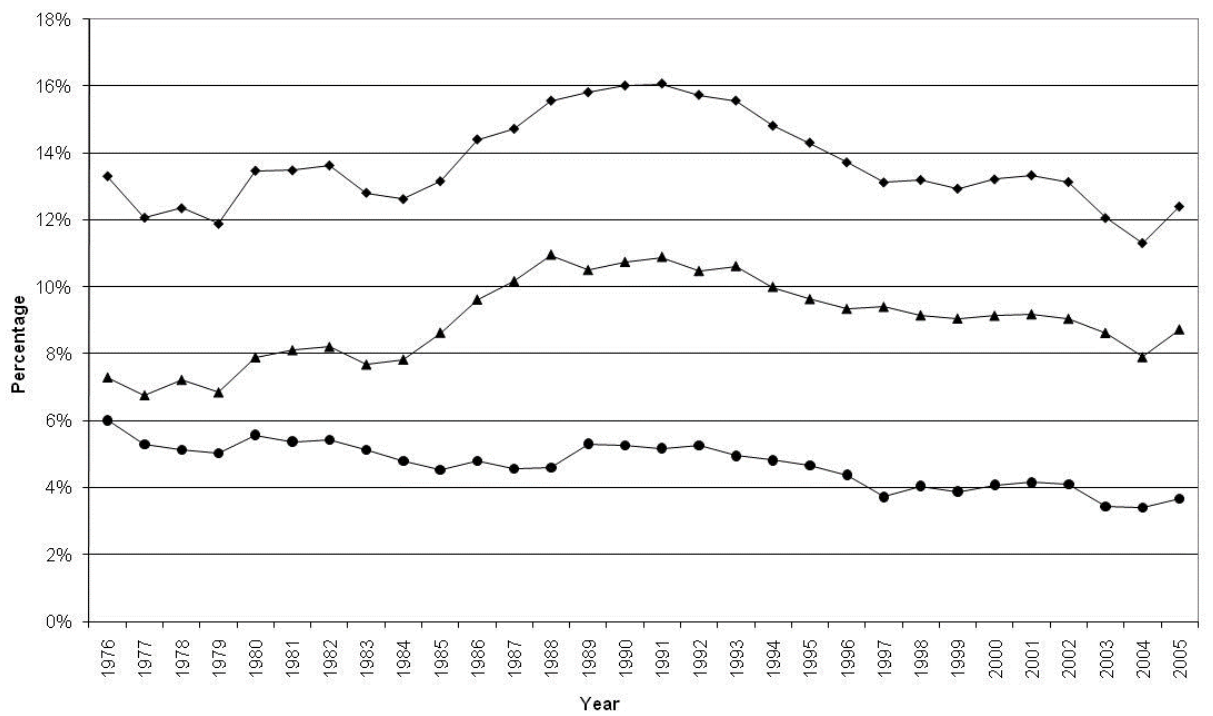

Figure 2. Student Parent Participation by Gender as a Percentage of Total Post-Secondary Participation, Labour Force Survey, Canada 1976-2005 


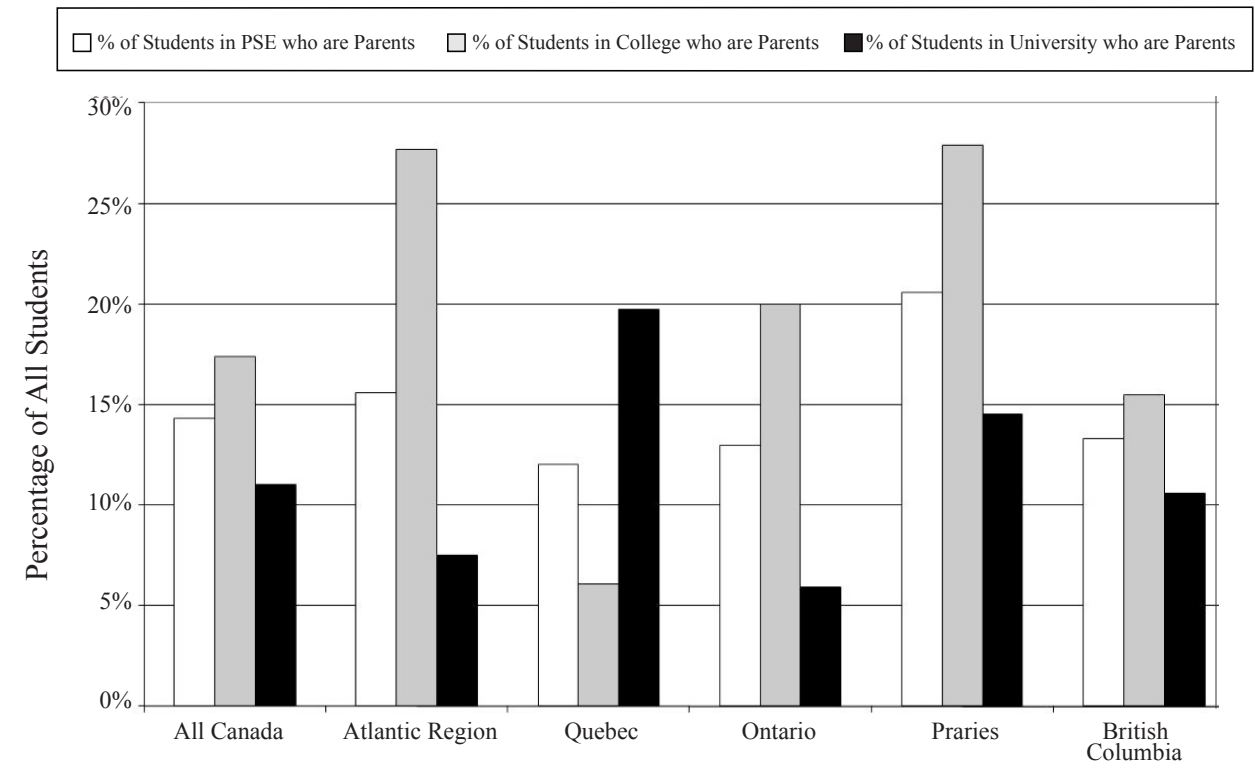

Figure 3. Student Parents by Type of Institution and Region as a Percentage of Total Post-Secondary Participation, Survey of Labour and Income Dynamics, 2004, Cross-Sectional Data

\section{A Closer Look at Participation Patterns}

Type of institution (LFS 1976 to 2005 data).

Growth in undergraduate enrolments occurred in both college and university programs for all post-secondary students, increasing by $116 \%$ (from 279,700 to 603,700 ) for colleges and by $106 \%$ (from 306,200 to 630,400 ) for universities from 1976 to 2005 (Table 1). While non-parent participation increased equally for colleges and universities at $113 \%$ for each, student parent increases were much higher at the college level (132\%) than at the university level (55\%).

Table 1.

Comparison of Growth in University and College Participation by Student Parents and Non-Parents, Labour Force Survey, Canada 1976-2005

\begin{tabular}{lrrrr}
\hline Student Type & 1976 & 2005 & \multicolumn{1}{c}{$\begin{array}{c}\text { Increase } \\
1976-2005\end{array}$} & $\%$ Increase \\
\cline { 1 - 2 } \cline { 5 - 6 }$\quad$ University Non-Parents & 270,100 & 574,600 & 304,500 & 113 \\
University Parents & 36,100 & 55,800 & 19,700 & 55 \\
Total University & 306,200 & 630,400 & 324,200 & 106 \\
\hline College Non-Parents & 237,800 & 506,500 & 268,600 & 113 \\
$\quad$ College Parents & 41,800 & 97,200 & 55,400 & 132 \\
Total College & 279,700 & 603,700 & 324,000 & 116 \\
\hline
\end{tabular}

Note. Table presented rounded to nearest 100; however, calculations made using original data so any apparent deviations in table are due to rounding. 


\section{Study status (LFS 1976 to 2005 data)}

Among all post-secondary students, full-time enrolment increased from 1976 to 2005 by $124 \%$ (Table 2). The increase in full-time enrolment by student parents over this time period was dramatically higher than the overall growth rate at $292 \%$ and also outpaced the rate of increase among non-parent students (116\%). Over the same time period, overall part-time enrolment increased by $75 \%$ with a higher increase by non-parent students (100\%) than student parents (33\%). As a consequence of the dramatic increase in full-time enrolments by student parents, while the proportion of full-time to part-time students for non-parents remained relatively stable at approximately $4: 1$, a sizable shift occurred for student parents. In 1976 the proportion of full-time to part-time student parents was approximately 1:3; however, by 2005 that proportion had shifted to almost 1:1.

Table 2.

Comparison of Growth in Full-and Part-Time Participation by Student Parents and Non-Parents, Labour Force Survey, Canada 1976-2005

\begin{tabular}{lrrrc}
\hline Student Type & 1976 & 2005 & $\begin{array}{c}\text { Increase } \\
1976-2005\end{array}$ & $\%$ Increase \\
\hline Full-Time Non-Parents & 406,700 & 848,600 & 471,900 & 116 \\
Full-Time Parents & 19,100 & 74,900 & 55,800 & 292 \\
Total Full-Time & 425,800 & 953,500 & 527,700 & 124 \\
\hline Part-Time Non-Parents & 101,200 & 202,400 & 101,300 & 100 \\
Part-Time Parents & 58,800 & 78,100 & 19,300 & 33 \\
Total Part-Time & 160,000 & 280,500 & 120,500 & 75 \\
\hline
\end{tabular}

Note. Table presented rounded to nearest 100; however, calculations made using original data so any apparent deviations in table are due to rounding.

\section{Age (LFS 1976 to 2005 data)}

Not surprisingly, student parents were found to be older than non-parent students. Approximately $90 \%$ of all non-parent students were in the 15-to-29-year-old age category for the entire time period, accounting for approximately $80 \%$ of all post-secondary students (Figure 4). Among student parents, the dominant age category is 30 to 44 years old, accounting for approximately $65 \%$ of all student parents and between $7 \%$ and 11\% of all post-secondary students between 1976 and 2005.

\section{Gender (LFS 1976 to 2005 data)}

Participation by female students drove much of the growth in post-secondary participation between 1976 and 2005, increasing by 149\% (Table 3). Female student parent participation rates actually outpaced female non-parents (152\% and $148 \%$, respectively). Growth in participation by male student parents was a mere $29 \%$ compared with an increase of $83 \%$ for male non-parents. Consequently, fe- 
$\bullet$ Parents 15-29 $\rightarrow$ Parents 30-44 $\rightarrow$ Parents 45-59 $\multimap$-Non-parents 15-29 $\neg$-Non-parents 30-44 $\neg-$ Non-parents 45-59

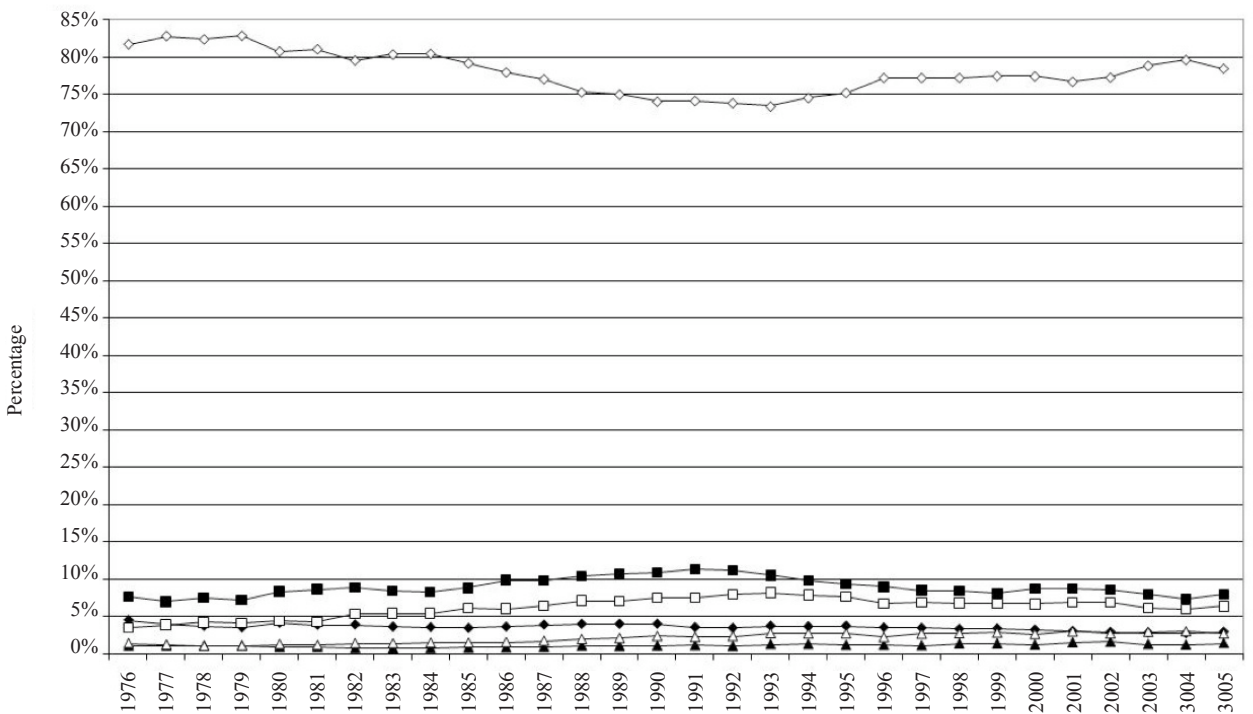

Figure 4. Participation of Student Parents and Non-Parents by Age Group as a Percentage of Total Post-Secondary Participation, Labour Force Survey, Canada 1976-2005

male student parents increased from 7\% of all post-secondary students in 1976 to 9\% in 2005 (Figure 2), but male student parent participation decreased from 6\% to $4 \%$ during the same period. While females have outnumbered males on postsecondary campuses since the mid-1980s, representing between $51 \%$ and $57 \%$ of all post-secondary students, student parents are even more likely to be female. Female student parents represented between $62 \%$ and $71 \%$ of all student parents from the mid-1980s up until 2005.

Table 3 .

Comparison of Student Parent and Non-Parent Growth in Participation by Gender, Labour Force Survey, Canada 1976-2005

\begin{tabular}{lllll}
\hline Student Type & \multicolumn{1}{c}{1976} & \multicolumn{1}{c}{2005} & \multicolumn{1}{c}{$\begin{array}{c}\text { Increase } \\
1976-2005\end{array}$} & \% Increase \\
\hline Female Non-Parents & 233,200 & 578,500 & 345,300 & 148 \\
Female Parents & 42,700 & 107,700 & 64,900 & 152 \\
Total Female & 275,900 & 686,200 & 410,200 & 149 \\
\hline Male Non-Parents & 274,700 & 502,500 & 227,800 & 83 \\
Male Parents & 35,200 & 45,400 & 10,200 & 29 \\
Total Male & 309,900 & 547,900 & 238,000 & 77 \\
\hline
\end{tabular}

Note. Table presented rounded to nearest 100; however, calculations made using original data so any apparent deviations in table are due to rounding. 
When disaggregated by type of institution, the substantial increase in college enrolment among student parents was apparently driven by female student parents. As a percentage of total post-secondary enrolment, female college student parents increased from less than 4\% in 1976 to more than 5\% in 2005 (Figure 5). Over the same time period, college male enrolment declined slightly from approximately $3 \%$ to $2 \%$. As a percentage of total post-secondary participation, female student parents in university remained relatively stable over the period at around $3 \%$, while male student parents declined from representing approximately $3 \%$ in 1976 to only $1 \%$ of total enrolment in 2005.

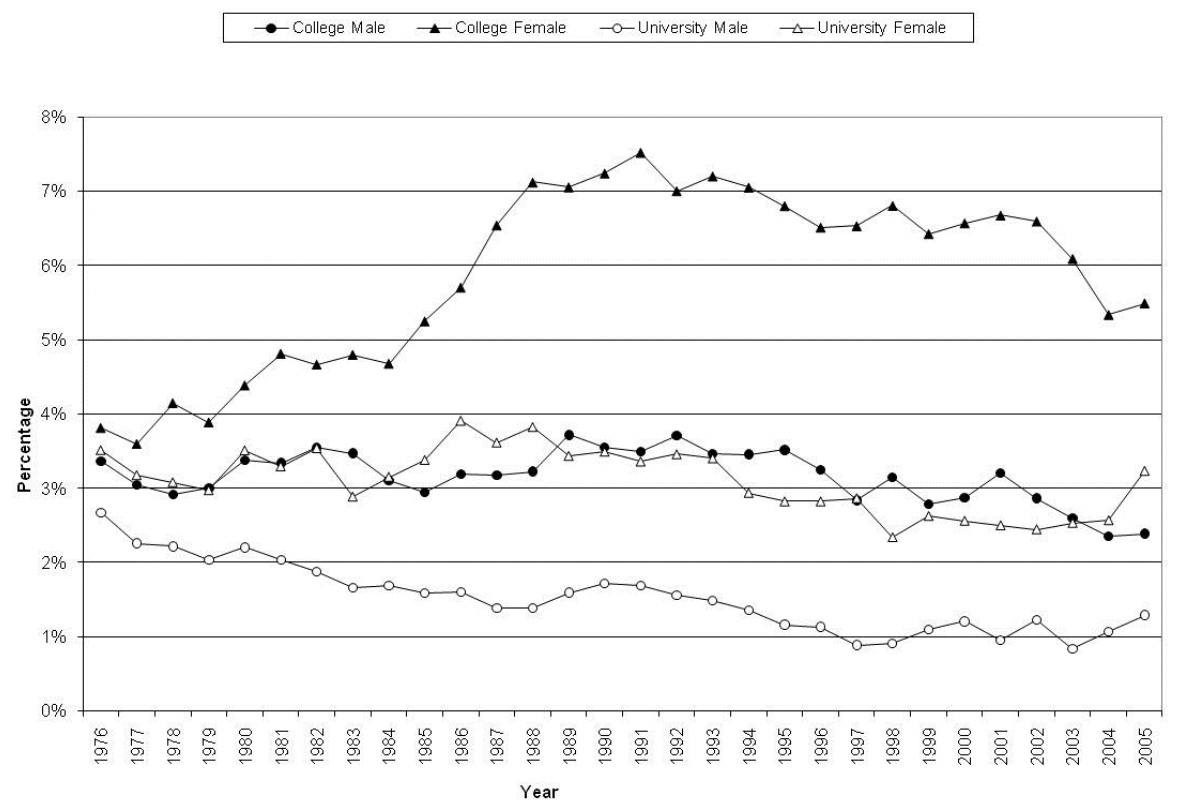

Figure 5. University / College Student Parent Participation by Gender as a Percentage of Total PostSecondary Participation, Labour Force Survey, Canada 1976-2005

\section{Marital status (LFS 1976 to 2005 data)}

A higher proportion of post-secondary student parents were partnered (including married and common-law) than single student parents (including those who were never married, divorced/separated, and widowed). In particular, married female student parents represented between $6 \%$ and $8 \%$ of total post-secondary enrolment between 1976 and 2005 (Figure 6) and accounted for between $44 \%$ and 55\% of all student parents. Single female student parents experienced considerable growth from 1976 to 1997, increasing from 1\% to 3\% of all post-secondary students (from 7,400 to 34,300 ), with some decline since then to just over $2 \%$. The participation of married male student parents has declined from $6 \%$ of all post-secondary students in 1976 to between 3\% and 4\% since 1997. Single male student parents represented 
less than $1 \%$ of total post-secondary participation throughout the time period. The increased participation of single female student parents and the declining representation of married male student parents, in particular, changed the overall ratio of married student parents to single student parents from 9:1 in 1976 to 4:1 in 2005.

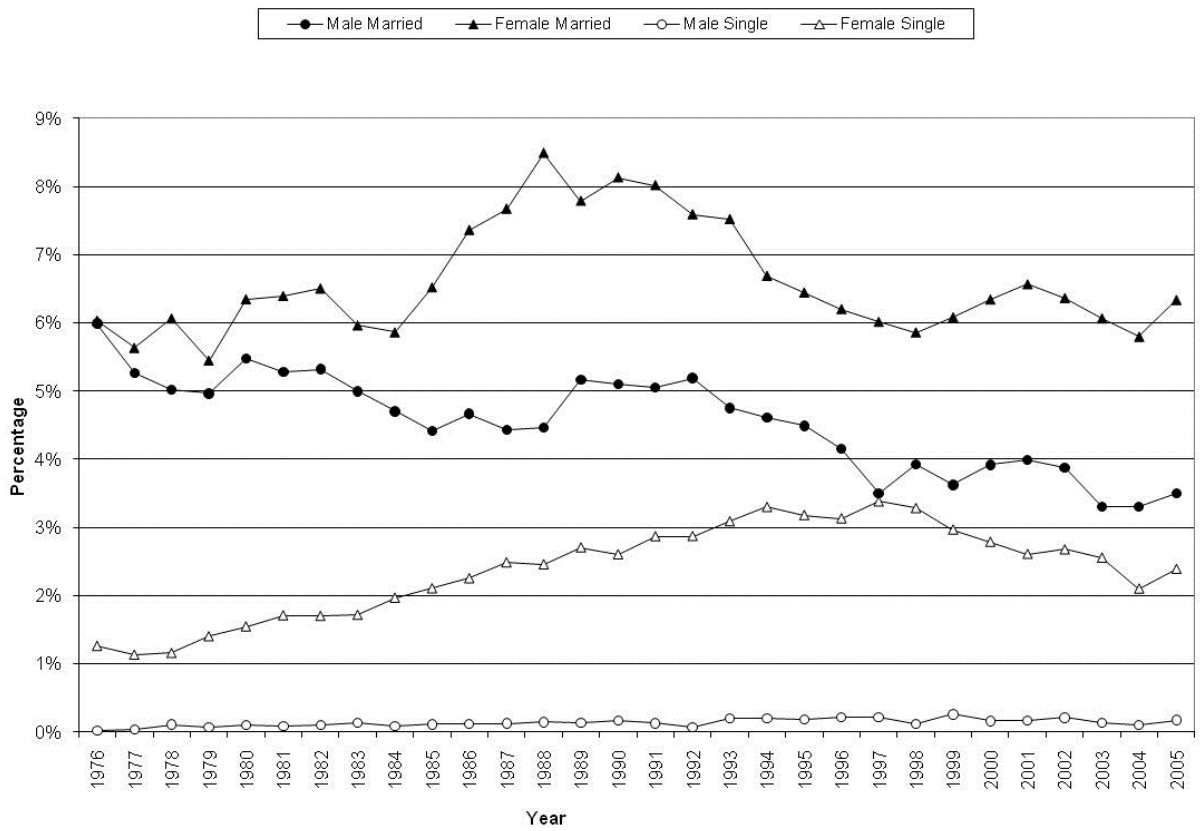

Figure 6. Student Parent Participation by Marital Status and Gender as a Percentage of Total PostSecondary Participation, Labour Force Survey, Canada 1976-2005

Employment (SLID 2004 data)

Although student parents and non-parents were equally likely to be employed (just over $80 \%$ ), student parents were more likely to be employed for the full year (55\% vs. $41 \%$ of non-parents) (Figure 7). Most likely to be employed for the full year were university student parents $(64 \%)$, followed by college student parents (50\%), college non-parents (42\%), and university non-parents (40\%).

Student parents studying on a part-time basis were more likely to be employed than part-time non-parents (95\% and $87 \%$, respectively) and those who were employed were more likely than non-parents to work throughout the year (77\% vs. 61\%) (Figure 8). When studying full-time, however, student parents were less likely to be employed than non-parents ( $71 \%$ vs. $80 \%$ ).

\section{Income (SLID 2004 data)}

Comparing the family incomes of student parents with those of childless students is difficult given that the childless students tend to be younger and are often living with and/or being supported by their own parents. This difficulty was reflected in findings of a higher family income for both university and college non-parents than 


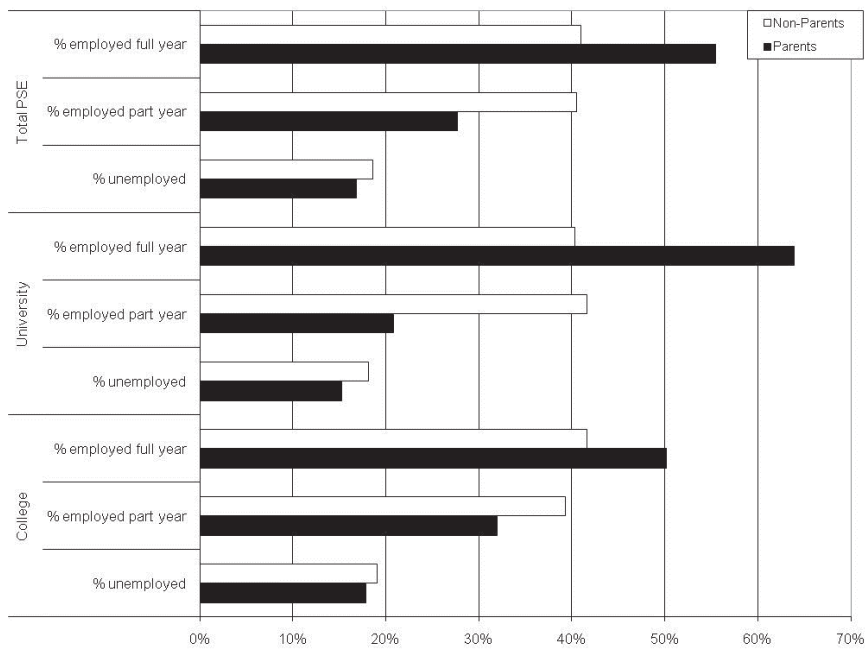

Figure 7. Labour Force Status of Student Parents and Non-Parents by Type of Institution, Survey of Labour and Income Dynamics, 2004, Cross-Sectional Data

Note. Unemployed includes unemployed all year; unemployed part year, not in the labour force part year; and not in the labour force all year. Employed part year includes: employed part year, unemployed part year; employed part year, not in the labour force part year; employed, unemployed, and not in the labour force during the year.

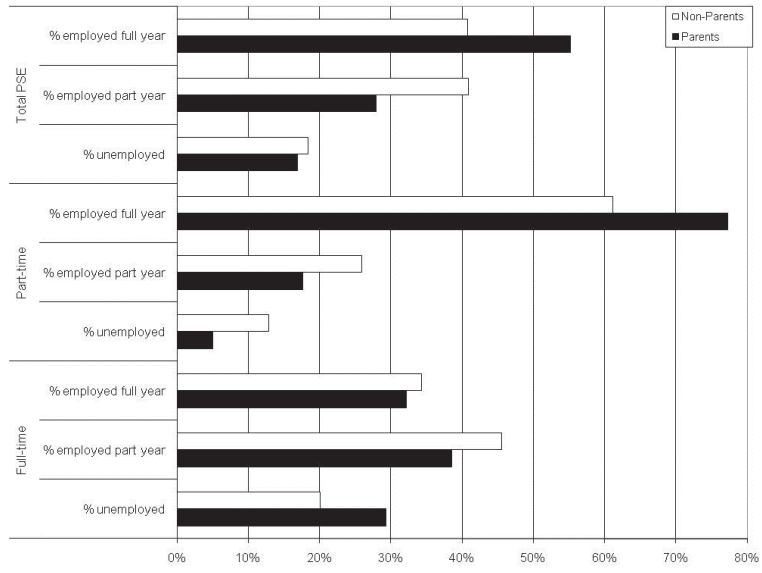

Figure 8. Labour Force Status of Student Parents and Non-Parents by Study Status, Survey of Labour and Income Dynamics, 2004, Cross-Sectional Data

Note. Unemployed includes unemployed all year; unemployed part year, not in the labour force part year; and not in the labour force all year. Employed part year includes: employed part year, unemployed part year; employed part year, not in the labour force part year; employed, unemployed, and not in the labour force during the year. 
student parents (Table 4). An examination of individual incomes found the reverse, with higher incomes for university and college student parents than non-parents.

Table 4.

After-Tax Income for Student Parents and Non-Parents, Survey of Labour and Income Dynamics, 2004

\begin{tabular}{lcccc}
\hline & \multicolumn{2}{c}{ Census Family After-Tax Income } & \multicolumn{2}{c}{ Individual After-Tax Income $^{\mathrm{b}}$} \\
\cline { 2 - 5 } Student Type & Mean & Median & Mean & Median \\
\hline Parents & & & \\
Not in PSE & $\$ 67,240$ & $\$ 59,034$ & $\$ 33,830$ & $\$ 28,680$ \\
In College & $\$ 52,793$ & $\$ 48,586$ & $\$ 23,844$ & $\$ 22,946$ \\
In University & $\$ 61,740$ & $\$ 63,579$ & $\$ 31,727$ & $\$ 28,278$ \\
\hline Non-Parents & & & & \\
Not in PSE & $\$ 52,646$ & $\$ 43,959$ & $\$ 25,527$ & $\$ 21,169$ \\
In College & $\$ 58,599$ & $\$ 52,660$ & $\$ 13,439$ & $\$ 9,536$ \\
In University & $\$ 69,004$ & $\$ 60,124$ & $\$ 12,527$ & $\$ 9,000$ \\
\hline
\end{tabular}

${ }^{a}$ Census Family After-tax income is defined as total income minus income tax.

${ }^{\mathrm{b}}$ Individual After-tax income is defined as total income minus income tax.

Among post-secondary students studying on a full-time basis, student parents were much more likely to be the major earner in the family compared to nonparents (56\% vs. 28\%) (Table 5). The reverse was true for those studying part-time, with non-parents being more likely to be the major earner than student parents (54\% and $46 \%$, respectively). Among both full-time and part-time post-secondary students, student parents were more likely to receive transfer payments or compensation (including Employment Insurance Benefits, Workers' Compensation, and Social Assistance) than non-parents. For those studying full-time, $42 \%$ of student parents received such forms of financial assistance compared to $8 \%$ of non-parents. For those studying part-time, $25 \%$ of student parents received compensation compared to $13 \%$ of non-parents.

Table 5.

Comparison of Student Parents and Non-Parents in PSE Programs, Survey of Labour and Income Dynamics, 2004

\begin{tabular}{lcc}
\hline Characteristic & Parents & Non-Parents \\
\hline Total Number in PSE & 287,000 & $1,730,700$ \\
Proportion & 14.3 & 85.7 \\
\% who are studying full-time and major earner ${ }^{\mathrm{a}}$ & 56.3 & 28.0 \\
$\%$ who are studying part-time and major earner & 46.2 & 53.7 \\
$\%$ who are studying full-time and receive compensation payments ${ }^{\mathrm{b}}$ & 42.4 & 8.3 \\
\% who are studying part-time and receive compensation payments & 25.0 & 13.1 \\
\hline
\end{tabular}

Note. Participation in PSE is defined as participation in a college or undergraduate university program lasting three or more months and leading to a certificate, diploma, or degree.

a A person in the same census family as his or her parents cannot be identified as the major income earner, even if his or her total income is highest among all census family members. For the purpose of this variable, the absolute value of total income is used. If more than one person has the same income, the major income earner is defined to be the oldest.

${ }^{\mathrm{b}}$ Compensation includes Employment Insurance Benefits, Workers' Compensation, and / or Social Assistance. 


\section{DISCUSSION AND IMPLICATIONS}

Student parents have constituted a significant minority population on postsecondary campuses in Canada over the 30-year period from 1976 to 2005, accounting for between $11 \%$ and $16 \%$ of total post-secondary enrolment. With an increasing need for retraining and further education because of the current economic climate, the likelihood of this population becoming an increasing presence on post-secondary campuses is great.

\section{Profiles of Student Parents in Canada}

The findings demonstrate that student parents are far from a homogeneous group as evidenced by differential enrolment patterns at colleges and universities, for those studying full- and part-time, for males and females, and based on marital status. Furthermore, the differences between student parents and non-parents demonstrated in these findings offer some insight into the unique challenges student parents face at PSE institutions.

Increasing enrolment by both student parents and non-parents over the 30year period is indicative of increasing access to and value placed on PSE. With growth in student parent participation being outpaced by that of non-parents, it seems that student parents have less access to PSE programs than traditional, non-parent students. Moreover, college programs appear to be more accessible to student parents, given the significantly higher increases in college compared to university enrolment over the 30 years.

The shift in the proportion of part-time to full-time study from 3:1 to almost 1:1 is noteworthy. Holmes (2005) found that student parents were more likely to study part-time. The increased full-time enrolment demonstrated by student parents suggests that this finding may no longer be the case (though student parents are still more likely to study on a part-time basis than non-parents). Growth in the proportion of student parents studying on a full-time basis may be related to increased accessibility to full-time programs through student loan programs and an increase in the flexibility of PSE programming. Older students have traditionally accessed PSE through continuing education and professional development programs often held in the evenings or through distance education. Technological and institutional changes allowing students more control over the time and place of their studies may be helping this population to access PSE programs.

Student parents were found to be older than the majority of post-secondary students, dominating the 30-to-44-year-old age category. This finding is not surprising for this group and supports previous findings (Holmes, 2005). It serves to highlight one of the challenges of being a student parent: not fitting in. Based on age, student parents are more likely to be peers with faculty and other staff on post-secondary campuses; however, by status they are peers with young, childless students. Not really fitting in with either group can cause student parents to feel out of place (van Rhijn \& Lero, 2008). In addition, as a majority of campus 
resources and student services are directed toward the dominant population, student parents may feel excluded or marginalized, with few supports or services available to meet their unique needs.

Female student parents represented a much larger proportion of the total student parent population than males. In addition, growth in female student parent participation increased over the time period, unlike males, whose participation rates declined. Although female students generally represent a larger proportion of all post-secondary students (parents and non-parents alike), student parents were even more likely to be female. The increasing enrolment by female student parents beginning in 1984 was especially evident among college students. Although we are unable make a definitive determination of why these increases occurred, it appears that college programs present a more accessible option. This rising enrolment occurred in the period before the significant tuition fee increases seen in the early 1990s (Corak, Lipps, \& Zhao, 2003; Luong, 2010), and it may be that lower tuition fees and shorter program durations made college a more attractive alternative for female student parents. The increasing tuition fees, in particular the double-digit increases seen in the early 1990s (Luong, 2010), could also account for the leveling off of female student parent enrolment demonstrated in our findings (Figures 5 \& 6). In addition, the notable increases in female labour force participation that occurred during the 1970s and 1980s (Beaudry \& Lemieux, 1999) may have contributed to the motivation of female student parents to obtain a post-secondary education as a path to a career. Although a policy review was conducted (Lero et al., 2007), no other substantial changes in relevant public policies were identified that may have contributed to the enrolment changes observed during this period.

Married student parents have continued to represent a greater proportion of the student parent population; however, increases in enrolment by single student parents, in particular single mothers, were noteworthy over the time period. This finding may be related to the addition of some programs and financial aid support directed at single parents that increased access to PSE.

Overall, student parents were more likely than non-parents to be employed for the full year. When examined by study status, part-time student parents were more likely to be employed than non-parents, providing some evidence that student parents who need to balance employment demands may do so by choosing to study on a part-time basis. Full-time student parents were less likely to be employed than non-parents. Possible reasons for this finding are that student parents who chose to study full-time may have had better access to adequate resources (e.g., student aid, household income, a working partner) which reduced their need to work. Full-time student parents might also have chosen not to work as a strategy to allow more time for their studies and family commitments. Employment decisions may also be related to employment and income restrictions on student financial aid; these restrictions might cause a full-time student parent to refrain from working not because they don't need the additional income, but rather to meet the eligibility requirements of their financial aid. 


\section{Limitations}

There are some limitations to the data sets used for this study. The SLID and LFS surveys are general population surveys and are not targeted to students. Neither of the surveys provided a direct measure of the level of university participation (i.e., undergraduate or graduate). Therefore, respondents were considered to be graduate students if they already had an undergraduate or graduate degree and were attending university. This assumption may have erroneously excluded some students who were completing a second undergraduate program or a professional certification or degree. Additionally, the analyses conducted for this study are descriptive and intended to provide an overview of student parent participation over time in Canada; analyses were limited to a trend study and betweengroup comparisons were not tested for statistical significance. Finally, student parents may also be members of groups that have traditionally been disadvantaged with respect to PSE participation (e.g., those who identify as visible minorities or are immigrants). This circumstance may compound the challenges of obtaining a post-secondary diploma or degree. Data from the 2006 census demonstrate that $19.8 \%$ of the total population were born outside the country and $16.2 \%$ identify as visible minorities (Statistics Canada, 2010). It is possible that these growing populations have contributed to the increases in enrolment numbers as well as the diversity of the student parent population. These considerations are important for future research.

\section{Implications for Policy \& Practice}

The findings presented in this paper support the hypothesis that participation patterns of student parents differ considerably from their traditional post-secondary student counterparts. They are more likely to enrol in college and study parttime. They are also older on average, more likely to be female, married, and employed for the full year. Finally, the findings related to income suggest that student parents bear the responsibility of financially providing for their families through employment and/or compensation payments. Despite supporting the hypothesis that student parents are distinct from traditional students, the findings also demonstrate that student parents are not a homogeneous group; they are a diverse group made up of a number of different sub-populations. The implications of this finding, in addition to the general finding of differences from traditional students, are important when considering recommendations for policy and practice.

Recognition of the differences in student parents' life situations and study patterns is the predominant implication for policy and practice. Student parents simply do not fit into the current models for program provision, student services, and also student finance. Student parents' may be benefited by policies providing flexible options for modes of study including part-time and distance options as well as the ability to start and stop programs in recognition of the diverse learning pathways of adult learners. In addition, policies that facilitate transition could 
allow student parents to begin study when they are ready to do so rather than delaying study for reasons related to finances, child care, or eligibility. Bridging and upgrading programs are recommended that could provide many student parents with the chance to build skills and confidence and to access information about navigating the post-secondary system. Finally, it is likely that student parents have less access to resources and referrals to resources than traditional post-secondary students because they are more likely to live off campus, have family responsibilities, and have a smaller peer network. This lack of access to information and resources (e.g., financial aid, learning services, and other institutional resources) may be detrimental in terms of accessing information that could help increase their ability to persist in and complete their studies. For these reasons, active targeting of resources to these students is recommended.

\section{Future Directions}

This study was designed as the first step in a program of research to advance understanding of Canadian PSE student parents. Future elements of the research include examination of student finances and loan use, specific challenges for single parents, and the nuanced experiences of student parents as they manage multiple roles.

Research exploring barriers to access for potential student parents is also recommended. It is vitally important to include parents who do participate in PSE as well as those who do not in order to develop an understanding of barriers. Although most institutions promote human rights and prohibit discrimination on the basis of factors including age, marital, and family status (Human Rights and Equity Office, n.d.) and actively promote the inclusion of diverse student populations in theory, there is little indication of policies or programs targeted to support either parents considering entering PSE or those currently enrolled.

Research is also required to investigate the apparent misfit of student parents with government and institutional policies designed to support the pursuit of PSE. These policies are typically designed for the traditional student population, often leaving student parents with limited eligibility and access to supports. It is necessary to carefully consider the ability of social programs, including social assistance, workers' compensation, and employment insurance, to support the pursuit of PSE for student parents. In addition, child care and other educational supports will be necessary elements in an integrated policy approach that supports all parents in furthering their education.

Finally, it is important to note that student parents have maintained a presence on college and university campuses across Canada for the past 30 years and many have been successful in completing their post-secondary programs. Research exploring the strategies and resources utilized by successful student parents to manage their multiple roles of school, family, and often employment is recommended on which evidence-based programs can be created. 


\section{CONCLUSIONS}

As student parents constitute a significant minority population on Canadian college and university campuses, a better understanding of student parents' experiences is required to reduce barriers to access and challenges to persistence and program completion for this population. This study serves as the first step in a program of research about student parents, providing a profile of their participation trends over time and an initial examination of potential challenges they could be facing. Further research is recommended to provide a more comprehensive understanding of this diverse population that can be used to guide policy-makers. It appears that public and institutional policies and practices affecting student parents should be reviewed to remove impediments to student parents' participation and persistence in PSE programs.

There are many benefits to enhancing access to post-secondary education for student parents. Lifelong learning enhances personal and social well-being, employment opportunities, and community engagement (Myers \& de Broucker, 2006). Beyond the social and economic benefits of post-secondary education for student parents and their families, benefits accrue because parents serve as important role models to their children. Children of parents who have attended PSE are more likely to attend PSE themselves (Berger, Motte, \& Parkin, 2007). Children are also likely to benefit from the supportive learning environment that student parents create in their homes. Policies and practices that encourage lifelong learning and skill development will require attention to the needs of diverse populations including student parents.

\section{REFERENCES}

Allen, M., \& Vaillancourt, C. (2004). Class of 2000: Profile of postsecondary graduates and student debt. Ottawa, ON: Culture, Tourism and the Centre for Education Statistics Division, Statistics Canada.

Beaudry, P., \& Lemieux, T. (1999). Evolution of the female labour force participation rate in Canada, 1976-1994: A cohort analysis. Canadian Business Economics, $7(2), 57-70$.

Berger, J., Motte, A., \& Parkin, A. (2007). The price of knowledge: Barriers to post-secondary education (3rd ed.). Retrieved from Canada Millennium Scholarship Foundation website: http://www.millenniumscholarships.ca/images/Publications / POK07_e.pdf

Berger, J., Motte, A., \& Parkin, A. (2009). The price of knowledge: Access and student finance in Canada. Retrieved from Canada Millennium Scholarship Foundation website: http:/ / www.millenniumscholarships.ca/en/ research/PriceKnowledge. html

Butlin, G. (1999). Determinants of post-secondary participation. Education Quarterly Review, 5(3), 9-35. 
Corak, M., Lipps, G., \& Zhao, J. (2003). Family income and participation in post-secondary participation. Analytical Studies Branch research paper series. Retrieved from Statistics Canada website: http://www.statcan.gc.ca/ pub/11f0019m/11f0019m2003210-eng.pdf

Dubois, J. (2006). Trends in student borrowing and pathways: Evidences from the 1990, 1995 and 2000 classes. Learning Policy Directorate, Strategic Policy and Planning. Retrieved from Human Resources and Skills Development Canada website: http: / / www.rhdcc-hrsdc.gc.ca/eng/cs/sp/hrsdc/lp/publications/2006-002850/ page00.shtml

EKOS Research Associates. (2003). Making ends meet: The 2001-2002 student financial survey. Montreal, QC: Canada Millennium Scholarship Foundation.

Grayson, J. P., \& Grayson, K. (2003). Research on retention and attrition. Retrieved from Canada Millennium Scholarship Foundation website: http:/ / www.millenniumscholarships.ca/images/Publications / retention_final.pdf

Holmes, D. (2005). Embracing differences: Post-secondary education among aboriginal students, students with children and students with disabilities. Retrieved from Canada Millennium Scholarship Foundation website: http:/ / www.millenniumscholarships.ca/images/Publications/embracing_en.pdf

Home, A. M. (1997). Learning the hard way: Role strain, stress, role demands, and support in multiple-role women students. Journal of Social Work Education, 33(2), 335-347.

Human Rights and Equity Office. (n.d.). Human rights. Retrieved from University of Guelph website: http:/ / www.uoguelph.ca/hre/hr.shtml

Lambert, M., Zeman, K., Allen, M., \& Bussière, P. (2004). Who pursues postsecondary education, who leave and why: Results from the Youth in Transition Survey. Culture, Tourism and the Centre for Education Statistics research paper. Retrieved from Statistics Canada website: http: / / dsp-psd.pwgsc.gc.ca/Collection/ Statcan/81-595-MIE/ 81-595-MIE2004026.pdf

Lero, D. S., Smit Quosai, T., \& van Rhijn, T. M. (2007). Access to post-secondary education for student parents: Final report. Submitted to Human Resources and Social Development Canada.

Looker, E. D. (1997). In search of credentials: Factors affecting young adults' participation in post-secondary education. Canadian Journal of Higher Education, $27(2), 1-36$.

Luong, M. (2010). The financial impact of student loans. Perspectives on Labour and Income, 11(1), 5-18.

Myers, K., \& de Broucker, P. (2006). Too many left behind: Canada's adult education and training system. Retrieved from Canadian Policy Research Networks website: http: / / cprn.org/documents/43977_en.pdf

Padula, M. A. (1994). Reentry women: A literature review with recommendations for counseling and research. Journal of Counseling and Development, 73(1), $10-16$. 
Pascarella, E. T., \& Terenzini, P. T. (2005). How college affects students. Volume 2: A third decade of research. San Francisco, CA: Jossey-Bass.

Statistics Canada. (2004). Canadian Labour Market at a Glance. Retrieved from Statistics Canada website: http:// www.statcan.ca/english/freepub/71-222XIE / 2004000 / chart-f37.htm

Statistics Canada. (2009). Persons in low income after tax, by prevalence in percent (2003 to 2007). CANSIM. Retrieved from Statistics Canada website: http:/ / www40.statcan.ca/101/ cst01/ famil19a-eng.htm

Statistics Canada. (2009a). Definitions, data sources and methods. Labour Force Survey (LFS). Retrieved from Statistics Canada website: http://www.statcan. gc.ca $/$ cgi-bin $/ \mathrm{imdb} / \mathrm{p} 2 \mathrm{SV}$.pl? Function $=$ getSurvey\&SDDS=3701\&lang $=\mathrm{en} \& \mathrm{db}=\mathrm{i}$ mdb\&adm $=8 \&$ dis $=2$

Statistics Canada. (2009b). Definitions, data sources and methods. Survey of Labour and Income Dynamics (SLID). Retrieved from Statistics Canada website: http:/ / www.statcan.gc.ca/ cgi-bin/imdb/p2SV.pl?Function=getSurvey\&SDDS= 3889\&lang $=\mathrm{en} \& \mathrm{db}=\mathrm{imdb} \& \mathrm{adm}=8 \&$ dis $=2 \# \mathrm{~b} 1$

Statistics Canada. (2010). Selected trend data for Canada, 1996, 2001 and 2006 censuses. Retrieved from Statistics Canada website: http:/ / www12.statcan.gc.ca/ census-recensement / 2006/ dp-pd/92-596/P1-2.cfm?TID=0\&Lang=eng\&T=PR\&P $\mathrm{RCODE}=01 \& \mathrm{GEOCODE}=01$

Ungerleider, C., \& Burns, T. (2004). The state and quality of Canadian public education. In D. Raphael (Ed.), Social Determinants of Health, Canadian Perspectives. Toronto, ON: Canadian Scholars' Press.

van Rhijn, T. M., \& Lero, D. S. (2008). Undergraduate student parents: A qualitative study of barriers and enablers to completing post-secondary education. Unpublished manuscript. University of Guelph. Guelph, ON.

\section{ENDNOTES}

1 In this project, a student parent was considered to be a person (aged 16 to 59) who had physical custody of one or more children under the age of 18 and was enrolled in a college, CEGEP, or university program leading to a certificate, diploma, or undergraduate degree. Students in CEGEP and college were combined under the college student designation.

2 The LFS is a nationwide survey conducted in the provinces and territories covering the civilian, non-institutionalized population 15 years of age and over. Excluded from the survey's coverage are persons living on reserves and other Aboriginal settlements in the provinces, full-time members of the Canadian Armed Forces, and the institutionalized population (total exclusion of less than $2 \%$ of the Canadian population aged 15 and over) (Statistics Canada, 2009a).

3 The Survey of Labour and Income Dynamics (SLID) is a nationwide survey sampling from all individuals in Canada 15 years of age and over. Excluded from the survey's coverage are residents of the Yukon, the Northwest Terri- 
tories, and Nunavut, residents of institutions, and persons living on reserves (total exclusion of less than 3\% of the Canadian population aged 15 and over) (Statistics Canada, 2009b). The 2004 cross-sectional data file included the following post-secondary students: all students in PSE, $N=2,018,486$; student parents, $n=287,780$.

\section{CONTACT INFORMATION}

Tricia van Rhijn

Department of Family Relations and Applied Nutrition

University of Guelph

Guelph ON N1G 2W1

tvanrhij@uoguelph.ca

Tricia van Rhijn is a PhD Candidate in the Family Relations and Human Development program at the University of Guelph and a Research Associate at the Centre for Families, Work and Well-Being. Her research interests include well-being, family relations, and various aspects of work-life integration (as well as school-life or school-work-life integration). Her current research project is a longitudinal study examining the experiences of mature students, including student parents, in postsecondary programs.

Dr. Trudy Smit Quosai is currently a Research Associate at the Partnerships for Children and Families Project at the Faculty of Social Work at Wilfred Laurier University. Dr. Smit Quosai holds a doctorate in Family Relations from the University of Guelph. Her research experience involves a large-scale, mixed-methods study that provided previously unavailable information about the profile of student parents in Canada and potential barriers and enablers to participation.

Dr. Donna S. Lero is a Professor in the Department of Family Relations and Applied Nutrition at the University of Guelph and holds the Jarislowsky Chair in Families and Work. She directs a program of research on public policy, workplace practices, and community supports in the University's Centre for Families, Work and Well-Being, which she co-founded. The Centre provides an important focus for interdisciplinary research involving faculty and students with shared interests in various aspects of work-life integration.

\section{ACKNOWLEDGEMENT}

This research was supported by a grant from Human Resources and Skills Development Canada. 